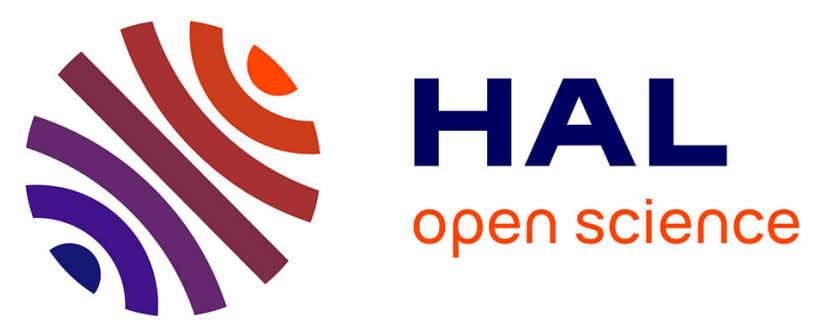

\title{
Validation of MODIS albedo products with high resolution albedo estimates from FORMOSAT-2
}

Maria Mira Sarrio, Dominique Courault, Albert Olioso, Marie Weiss, Olivier Marloie, Frédéric Baret, Olivier Hagolle, Belen Gallego-Elvira

\section{To cite this version:}

Maria Mira Sarrio, Dominique Courault, Albert Olioso, Marie Weiss, Olivier Marloie, et al.. Validation of MODIS albedo products with high resolution albedo estimates from FORMOSAT-2. International Geoscience and Remote Sensing Symposium, Institute of Electrical and Electronics Engineers (IEEE). New-York, USA., Jul 2013, Melbourne, Australia. 10.1109/IGARSS.2013.6723520 hal-01189890

\section{HAL Id: hal-01189890 https://hal.science/hal-01189890}

Submitted on 1 Sep 2015

HAL is a multi-disciplinary open access archive for the deposit and dissemination of scientific research documents, whether they are published or not. The documents may come from teaching and research institutions in France or abroad, or from public or private research centers.
L'archive ouverte pluridisciplinaire HAL, est destinée au dépôt et à la diffusion de documents scientifiques de niveau recherche, publiés ou non, émanant des établissements d'enseignement et de recherche français ou étrangers, des laboratoires publics ou privés. 


\title{
VALIDATION OF MODIS ALBEDO PRODUCTS WITH HIGH RESOLUTION ALBEDO ESTIMATES FROM FORMOSAT-2
}

\author{
M. Mira (1, 2), D. Courault (1), A. Olioso (1), M. Weiss (1), O. Marloie (1), F. Baret (1), \\ O. Hagolle (3), B. Gallego-Elvira (1). \\ (1) UMR 1114 EMMAH, INRA, F-84914 Avignon, France \\ (1) UMR1114 EMMAH, UAPV, Université d'Avignon, F-84000 Avignon, France \\ (2) University of Valencia, Dep. of Earth Physics and Thermodynamics, C/ Dr. Moliner 50, 46100 \\ Burjassot, Spain \\ (3) CNES-CESBIO, BPI 811, 18 Avenue E. Berlin, 31401 Toulouse Cedex 9, France \\ Email: maria.mira@uv.es
}

\begin{abstract}
Among MODIS products (freely available to the scientific community from 2001), albedo data (MCD43B3) are 16 days composites at $1 \mathrm{~km}$ spatial resolution, widely used for various applications in climate models, but which still remains difficult to validate. The objective of this study is to propose a method to validate these products with high spatial and temporal resolution data. 31 FORMOSAT-2 images acquired over a small region in the South-Eastern France at $8 \mathrm{~m}$ for spatial resolution were aggregated at MODIS resolution using a Point Spread Function. The correlation coefficient resulting from comparisons between albedo MODIS and the 1-km FORMOSAT-2 albedos varied from 0.93 to 0.98 , which show reasonably accurate results for this study area.
\end{abstract}

Index Terms - albedo, high resolution, aggregation, MODIS validation

\section{INTRODUCTION}

Land surface broadband albedo is a critical variable affecting the Earth's climate. It has been well recognized that surface albedo is among the main radiative uncertainties in current climate modeling. The NASA Earth Observing System (EOS) program provides series of high-level land surface products including albedo at $1 \mathrm{~km}$ spatial resolution on a 16 day cycle derived from Moderate Resolution Imaging Spectroradiometer (MODIS) reflectances [1]. These data are very useful for various operational applications since they are pre-processed, free and readily available to the scientific community. However, validation of such products still remains problematic because ground point-based measurements are not suitable for direct comparisons with coarse or middle spatial resolution satellite data over heterogeneous landscapes. Individual point-based measurements may not be representative of the surrounding area, unless the landcover, substrate, etc., in the region are reasonably homogeneous [2].

To deal with such problem, the point data can be aggregated to high-resolution images for a first step of the validation, and then compared with coarser resolution images, such as MODIS [3]. A common misconception is that the observational footprint of a sensor is the geometric projection of a rectangular pixel onto the Earth's surface [4]. The footprint rather depends on the instrument's Point Spread Function (PSF), which describes how the electromagnetic radiation coming from a point source is spread over the image plane as it is recorded by the imaging instrument [5]. MODIS is a whiskbroom scanner whose integration time as the rotating mirror scans the Earth is nearly a whole detector width [8] causing much higher spatial inter-pixel correlation in the cross-track direction than in the along-track direction. The large cross-track size of the MODIS PSF is caused by the image motion blur at each pixel. Susaki et al. (2007) [9] conducted a validation of MODIS albedo products of paddy fields in Japan, by comparing them with point-based albedo and 1-km ASTER (Advanced Spaceborne Thermal Emission and Reflection Radiometer) and ETM+ (Enhanced Thematic Mapper Plus) aggregated albedo using the PSF. The accuracy of MODIS albedo products obtained for paddy fields was within approximately 0.026 by absolute value and $15.1 \%$ by relative value. The objective of this study is to propose a similar approach to validate the MODIS albedo product from the use of high spatial and temporal resolution data acquired on various surface types. 


\section{METHODS AND DATA}

To overcome the difficulty of the scaling problem, highresolution images were aggregated through PSF of MODIS. The optimum PSF of MODIS was first assessed. Thirty one cloud free images of FORMOSAT2 $(28 \times 24 \mathrm{~km}$ scan with a pixel of $8 \mathrm{~m}$ for spatial resolution, www.astriumgeo.com/en/160-formosat-2) were acquired from March to October 2006 with a constant viewing angle over a small region called "La Crau", located in the lower Rhône Valley, South Eastern France (Fig1). La Crau is mainly a flat area which presents a wide variety of surfaces including dry and irrigated grasslands, wetlands and various crops. Climate is typically Mediterranean. The largest part of the high resolution image is covered by a specific dry grass ecosystem (locally termed 'coussouls'), which represents the only dry ecosystem in Europe. It corresponds to a large and flat stony area of more than 7400 hectares at the center of the Crau area.

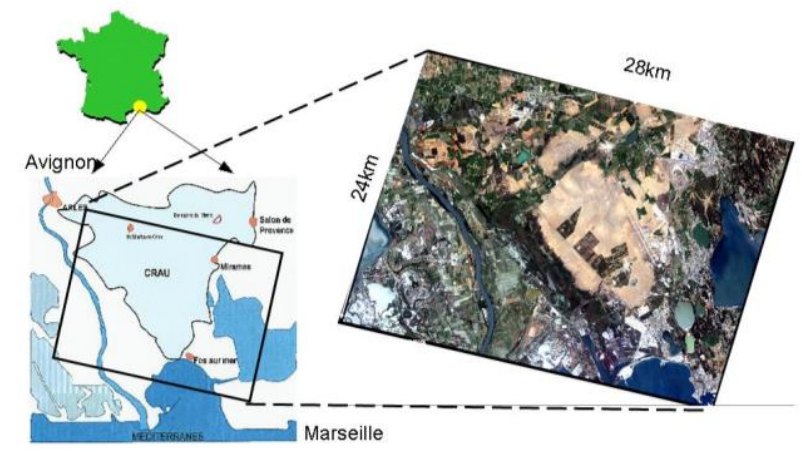

Fig 1. Location of the studied area, and the footprint of the FORMOSAT-2 image

FORMOSAT-2 albedo was estimated following the NarrowTo-Broadband conversion method, described in [7] and previously validated against ground measurements over different surfaces from the Crau-Camargue [10] (fig 2) according to the following equation:

Albedo $_{\text {FORMOSAT-2 }}=0.619 * \mathrm{~b} 3+0.402 * \mathrm{~b} 4$

where $\mathrm{b} 3$ and $\mathrm{b} 4$ are the red and near infrared spectral bands respectively from FORMOSAT-2.

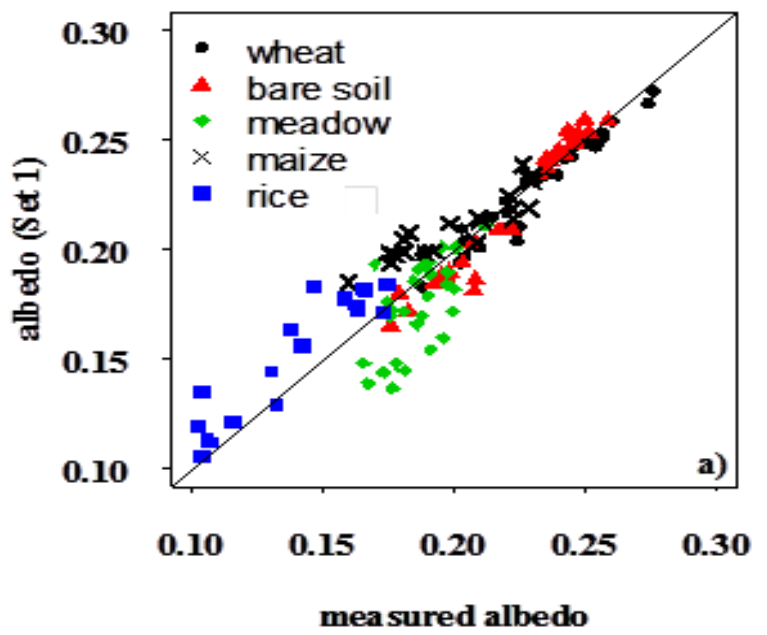

Fig 2. Comparison between ground based measured albedo and FORMOSAT-2 retrievals based on the coefficients of the multiple linear regression described in [7]. Data correspond to the leaveone-out validation data set. The 5 fields are identified by different symbols (RMSE=0.015).

The FORMOSAT area is included into an unique MODIS tile (i.e., h18v04). About 10 x 21 equivalent MODIS pixels were finally considered for albedo comparison after aggregation, and geometric fittings.

As no measurements were made on water and urban areas to validate estimation of FORMOSAT albedo, mean typical values computed from MODIS data at each date and were considered into the FORMOSAT scenes for thiese specific landuse classes to look for the PSF.

Actual albedo MODIS was estimated from directional hemispherical albedo (black-sky albedo, BSA) and bihemispherical albedo (white-sky albedo, WSA) in the shortwave spectral range, and a fraction of diffuse skylight $(\mathrm{S})$, which varies according to optical depth at 550nm $\tau(\lambda)$, $\theta$ the solar zenith angle, and $\lambda$ the wavelength.

$$
\begin{aligned}
\text { Albedo }_{\text {MODIS }}= & (1-S(\theta, \tau(\lambda))) \text { Albedo }_{\mathrm{BSA}}+ \\
& S(\theta, \tau(\lambda)) \text { Albedo }_{\mathrm{WSA}}
\end{aligned}
$$

Data from MODIS spectroradiometer on board Terra and Aqua satellites were used, providing images at a spatial resolution of $1 \mathrm{~km}$ and a temporal resolution of 8 days. Quality assurance information from MOD43 was also considered.

Note that albedo MODIS is created using a combination of data from different bands, leading to a particular PSF. MODIS PSF becomes triangular when integrated during the time necessary to record one measurement. The specific characterization of albedo MODIS's PSF was carried out in this study. The PSF, modeled as a Gaussian-like shape (fig 3), was characterized by the value of its Full Width at Half 
Maximum $(F W H M)$, both in the cross-track $(x)$ and alongtrack $(y)$ coordinates in the object space.

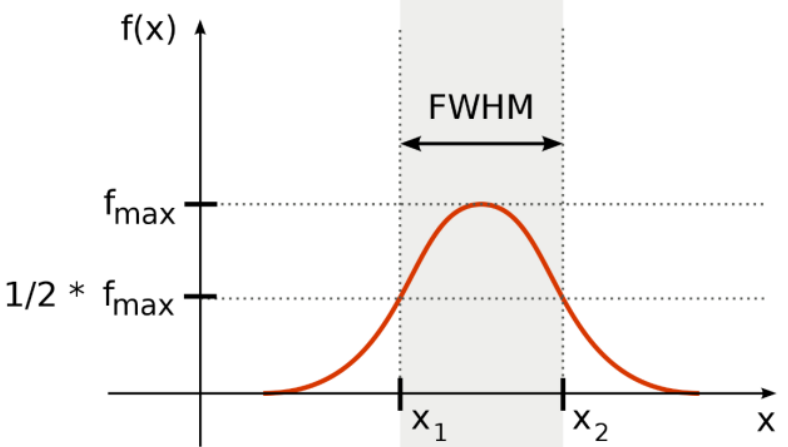

Fig 3. Definition of FWHM (Full Width at Half Maximum) on the the Gaussian like shape, used to model PSF.

\section{RESULTS}

Figure 4 shows the comparison between original albedo maps acquired at $8-\mathrm{m}$ (by FORMOSAT-2) and 1-km (by MODIS) spatial resolution, and the 1-km aggregated map through the PSF for one date: June $11^{\text {th }}$ 2006. Figure 5 displays the corresponding correlation obtained between these two images.

The accuracy appears satisfactory. A slight overestimation is observed for low values of MODIS albedo compared to FORMOSAT estimations. These points corresponded to water areas where mean values were taken because no measurements were available for validation.

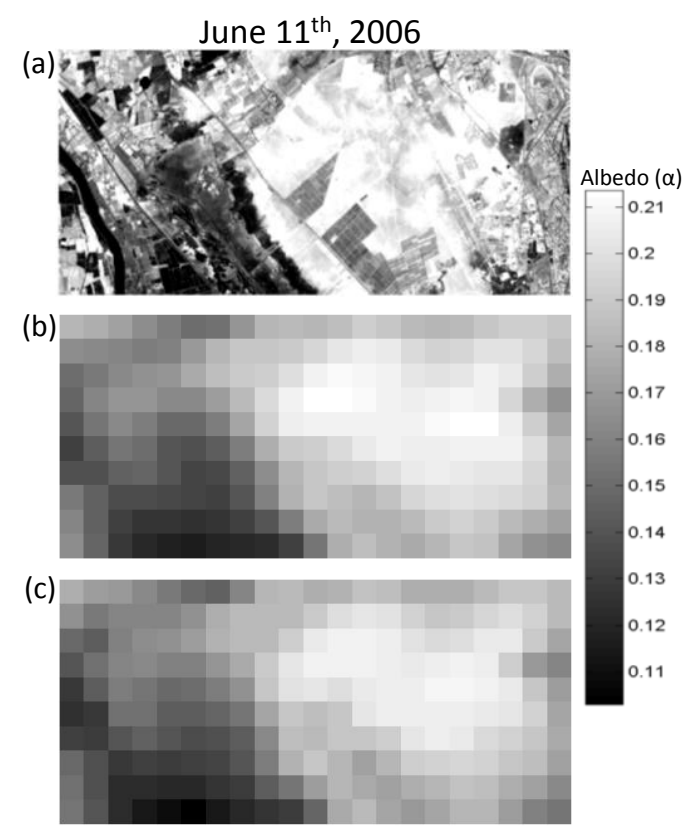

Fig 4. Albedo maps acquired on June $11^{\text {th }}, 2006$ over the Crau area, south-eastern France, corresponding to estimates from (a) FORMOSAT-2 (8 m spatial resolution), calculated following the Narrow-To-Broadband conversion method; (b) FORMOSAT-2 data aggregated from $8 \mathrm{~m}$ to $1000 \mathrm{~m}$ using the PSF from MODIS; (c) MODIS product MCD43B3 $(1 \mathrm{~km})$.

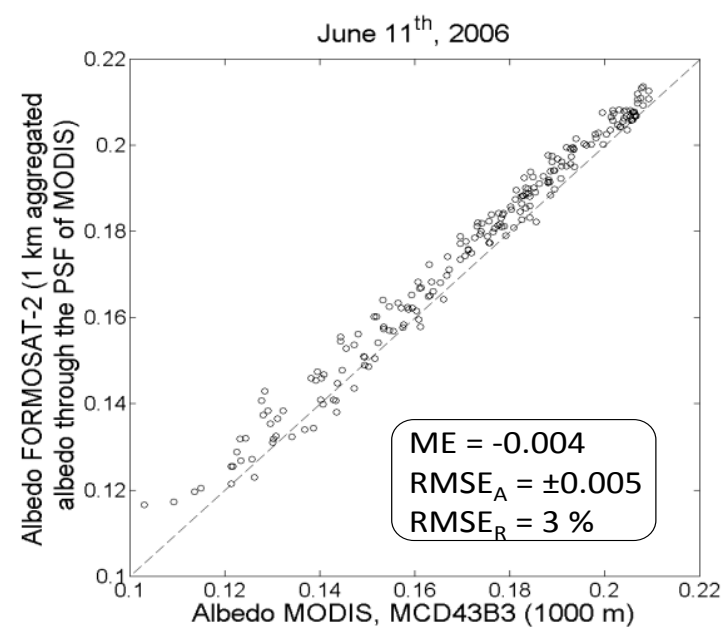

Fig 5. Comparison between albedo MODIS product MCD43B3 (1 $\mathrm{km})$ and $1 \mathrm{~km}$ aggregated albedo obtained through PSF of MODIS using FORMOSAT- 2 data ( $8 \mathrm{~m}$ original spatial resolution). Data from images acquired on June $11^{\text {th }}, 2006$ over the Crau area, southeastern France. Are also indicated the performances in terms of bias $(\mathrm{ME})$, absolute $\left(\mathrm{RMSE}_{\mathrm{A}}\right)$ and relative $\left(\mathrm{RMSE}_{\mathrm{R}}\right)$.

Figure 6 shows the variability of the correlation coefficients obtained between MODIS and FORMOSAT aggregated area at $1 \mathrm{~km}$ for different $F W H M$ values in $x$ and $y$ obtained for the 29 June 2006.

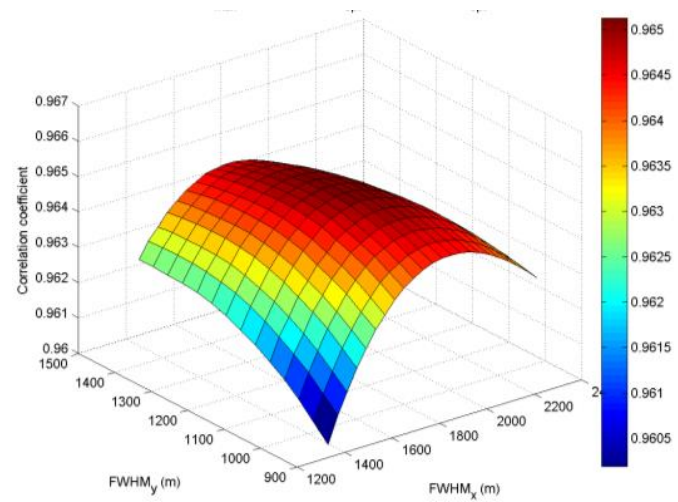

Fig 6. Evolution of the correlation coefficient as a function of the FWHM size along the $\mathrm{X}$ and $\mathrm{Y}$ axis. Values from the $\left(\mathrm{XL}_{\mathrm{HR}}, \mathrm{YL}_{\mathrm{HR}}\right)$ (up lower) position giving the maximum correlation coefficient.

The best performances obtained for MODIS were for PSFs with FWHMx varying from $1400 \mathrm{~m}$ to $2360 \mathrm{~m}$, and with FWHMy from 920 to $1640 \mathrm{~m}$ as shown in figure 7 . 


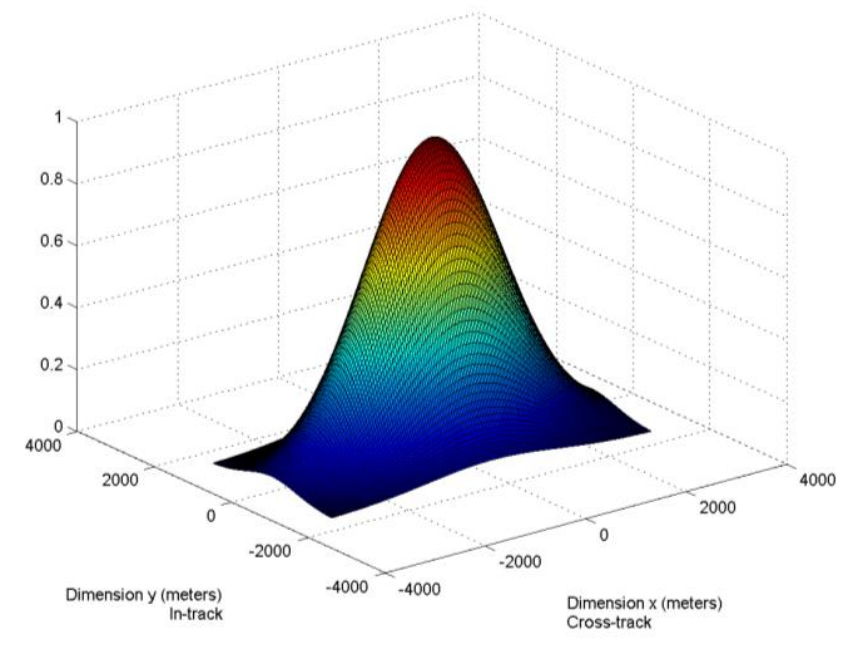

Fig 7. Caracterisation of the PSF giving the optimum correlation coefficient for June $11^{\text {th }} 2006$ according to Full Width at Half Maximum $(F W H M)$, both in the cross-track $(x)$ and along-track $(y)$ coordinates.

The correlation coefficient resulting from the comparisons between albedo MODIS and the 1-km FORMOSAT-2 albedos obtained for all the studied dates varied from 0.926 to 0.992 , which is quite good. The analysis of all images shows a bias varying from -0.008 to +0.008 , and an absolute $\left(\mathrm{RMSE}_{\mathrm{A}}\right)$ and relative $\left(\mathrm{RMSE}_{\mathrm{R}}\right)$ Root Mean Square Error from \pm 0.004 to \pm 0.011 (and from $2 \%$ to $7 \%$, respectively).

\section{CONCLUSION}

These results show that MODIS albedo products are reasonably accurate for our study area, and can be used in various models to estimate evapotranspiration at regional scale for example. The methodology presented here could be equally useful for other validation sites and/or validating similar land surface products of other environmental satellite systems. Validating these free land surface products is important because their accuracy is critical for the scientific community for various applications. Any feedback from the validation activity helps also and improves the generation of these products.

This work was within the frame of the European project SIRRIMED and with the support of CNES through the TOSCA research calls.

SIRRIMED: Sustainable use of IRRIgation water in the MEDiterranean region, FP7 European Commission CNES: Centre National d'Études Spatiales (France)

TOSCA: Earth, Ocean, continental Surfaces and Atmosphere

\section{REFERENCES}

[1] C.B. Schaaf, F. Gao, A.H. Strahler, W. Lucht, X.W. Li, T. Tsang, N.C. Strugnell, X.Z. Zhang, Y.F. Jin, J.P. Muller, P. Lewis, M. Barnsley, P. Hobson, M. Disney, G. Roberts, M. Dunderdale, C. Doll, R.P. d'Entremont, B.X. Hu, S.L. Liang, J.L. Privette, and D. Roy, "First operational BRDF, albedo nadir reflectance products from MODIS", Remote Sensing of Environment, 83, pp 135-148, 2002.

[2] P. Minnis, S. Mayor, W.L. Smith, and D.F. Young, "Asymmetry in the diurnal variation of surface albedo", Ieee Transactions on Geoscience and Remote Sensing, 35, pp 879-891, 1997.

[3] S. Liang,, H. Fang, M. Chen, C.J. Shuey, C. Walthall, C. Daughtry, J. Morisette, C. Schaaf, and A. Strahler, "Validating MODIS land surface reflectance and albedo products: methods and preliminary results", Remote Sensing of Environment, 83, pp 149$162,2002$.

[4] A.P. Cracknell, "Synergy in remote sensing - what's in a pixel?", International Journal of Remote Sensing, 19, pp 20252047, 1998.

[5] G. Duveiller,F. Baret, and P. Defourny, "Crop specific green area index retrieval from MODIS data at regional scale by controlling pixel-target adequacy", Remote Sensing of Environment, 115, pp 2686-2701, 2011.

[6] A.H. Strahler, and L.P. Muller, "MODIS BRDF/Albedo product: Algorithm theoretical basis document", NASA EOS MODIs Doc. Version 5. [Online] ». Available: http://modis.gsfc.nasa.gov/data/atbd/atbd_mod09.pdf, 1999.

[7] A. Bsaibes, D. Courault, F. Baret, M. Weiss, A. Olioso, F. Jacob, O. Hagolle, O. Marloie, N. Bertrand, V. Desfond, and F. Kzemipour," Albedo and LAI estimates from FORMOSAT-2 data for crop monitoring", Remote Sensing of Environment, 113, pp.716-729, 2009.

[8] Schowengerdt . "Remote sensing: Models and methods for image processing", 3rd edition. San Diego: Academic Press. 2007.

[9] J.,Susaki, Y., Yasuoka, K., Kajiwara, Y. Honda, and K. Hara, K. "Validation of MODIS albedo products of paddy fields in Japan". Ieee Transactions on Geoscience and Remote Sensing, 45, 206-217, 2007.

[10]. D. Courault, A. Bsaibes , E. Kpemlie, R., Hadria, O., Hagolle , O., Marloie, JF., Hanocq, Olioso, Bertrand, V., Desfonds, "Assessing the Potentialities of FORMOSAT-2 Data for Water and Crop Monitoring at Small Regional Scale in South-Eastern France". Sensors, 8, 3460-3481, 2008 